\title{
Ações Educativas em Saúde no Campo do Envelhecimento
}

\author{
Health Educational Actions in the Field of Aging
}

\author{
Maria Helena de Jesus Bernardo, Adriana de Jesus Garcia Pinto², Bruna Carolina Pelaggi Macedo ${ }^{3}$, \\ Dayara da Silva Ferreira ${ }^{4}$, Roberta Maia Silveira ${ }^{5}$
}

\begin{abstract}
1 Docente, coordenadora do projeto, assistente social e preceptora de residência multiprofissional em saúde do idoso. Faculdade de Serviço Social (FSS) e Núcleo de Atenção ao Idoso vinculado à Universidade Aberta da Terceira Idade do Hospital Universitário Pedro Ernesto da Universidade do Estado do Rio de Janeiro (NAI-UNATI-HUPE/UERJ), Brasil. E-mail: helenabernardo@uol.com.br 2 Estagiária de Serviço Social e bolsista de extensão do Projeto de Promoção da Saúde (PPS) do Núcleo de Atenção ao Idoso vinculado à Universidade Aberta da Terceira Idade do Hospital Universitário Pedro Ernesto da Universidade do Estado do Rio de Janeiro (NAI/UNATI/UERJ), Brasil. E-mail: adrianadejesusgarciapinto@gmail.com

3 Estagiária de Serviço Social e bolsista de extensão do Projeto Ações Educativas em Saúde no Campo do Envelhecimento (março a dezembro de 2015). Faculdade de Serviço Social (FSS) e Núcleo de Atenção ao Idoso vinculado à Universidade Aberta da Terceira Idade do Hospital Universitário Pedro Ernesto da Universidade do Estado do Rio de Janeiro (NAI/UNATI/UERJ), Brasil.

E-mail: brunapelaggi@hotmail.com

4 Bolsista de extensão do Projeto Ações Educativas em Saúde no Campo do Envelhecimento (junho de 2013 a dezembro de 2014), residente do programa multidisciplinar em saúde do idoso Faculdade de Serviço Social (FSS) e Núcleo de Atenção ao Idoso vinculado à Universidade Aberta da Terceira Idade do Hospital Universitário Pedro Ernesto da Universidade do Estado do Rio de Janeiro (NAI/UNATI/UERJ), Brasil. E-mail: dayara.ferreira@hotmail.com

5 Estagiária de Serviço Social e bolsista de extensão do Projeto Ações Educativas em Saúde no Campo do Envelhecimento - $9^{\circ}$ período. Faculdade de Serviço Social (FSS) e Núcleo de Atenção ao Idoso vinculado à Universidade Aberta da Terceira Idade do Hospital Universitário Pedro Ernesto da Universidade do Estado do Rio de Janeiro (NAI/UNATI/UERJ), Brasil. E-mail: rmaia@hotmail.com
\end{abstract}

Recebido em: 22/07/2016 | Aprovado em: 23/04/2017

DOI: $10.12957 /$ interag.2017.24776

\section{Resumo}

O artigo apresenta os resultados de pesquisa bibliográfica e documental realizada no âmbito da extensão universitária do projeto Ações Educativas em Saúde no Campo do Envelhecimento (FSS-UERJ). $\mathrm{O}$ referido projeto em parceria com o projeto de Promoção da Saúde (PPS) do Núcleo de Atenção ao idoso/UnATI/UERJ, desenvolve diversas modalidades educativas e de caráter interdisciplinar dirigidas ao público idoso. Para esse trabalho abordaremos o Grupo Roda da Saúde, uma das ações realizadas. Serão apresentados os dados referentes ao período de 2012 a 2015 sobre os seguintes eixos: grupos realizados, idosos e profissionais envolvidos, participações, temas debatidos, materiais socioeducativos construídos, bem como uma avaliação qualitativa do processo de assessoria junto às equipes de coordenadores e profissionais, e o impacto na formação do aluno de Serviço Social. Os resultados demonstram que as

\begin{abstract}
The article presents the results of bibliographical and documentary research carried out in the university extension realm of the "Health Educational Actions in the Field of Aging" project. This project in partnership with the Health Promotion Project (HPP) of the Care Center for the EIderly / UnATI / UERJ, develops a variety of educational and interdisciplinary methods aimed at the elderly community. In this paper, we will cover the group Roda da Saúde, one of the actions implemented through the proposal. Data are going to be presented, pertaining to the years 2012 through 2015, on the following areas: organized groups, seniors and professionals involved, participation, discussed themes, socio-educational materials built, as well as a qualitative assessment of the advisory process of the teams of coordinators and professionals, and the impact on the education of Social Service students. The results show that educational practices related to health, when guided by a critical bias, are potential
\end{abstract}


práticas educativas em saúde, quando norteadas por um viés crítico, constituem potenciais estratégias no fomento a maior participação dos usuários no espaço institucional e nas lutas coletivas por melhores condições de vida, de saúde e de trabalho. Coaduna-se com a perspectiva da educação popular em saúde, concepção que valoriza o diálogo, a horizontalidade das relações e a integração entre profissionais e usuários. No âmbito do ensino e da assessoria, o projeto viabiliza a capacitação de profissionais e de graduandos, interferindo na formação e estimulando posturas profissionais devidamente contextualizadas com as reais necessidades dos idosos. Para o aluno de Serviço Social, a experiência materializa e articula as dimensões constitutivas da profissão, corroborando o compromisso com a equidade e a justiça social.

Palavras-chave: Saúde; Envelhecimento; Educação em Saúde.

Área temática: Saúde

Linha de extensão: Saúde humana strategies for the promotion of a greater participation of users in the institutional space and for the collective disputes for better living, health and work conditions. It is consistent with the perspective of popular education in regards to health, a concept that values dialogue, the horizontality of relations and the integration between professionals and users. In the context of education and advisory services, the project enables the education of professionals and undergraduate students, interfering with their instruction and encouraging professional attitudes which are appropriate to the actual needs of the elderly. For the Social Service student, the experience materializes and articulates the constitutive dimensions of the profession, confirming their commitment to equity and social justice.

Keywords: Health; Aging; Health Education.

\section{Introdução}

O projeto Ações Educativas em Saúde no Campo do Envelhecimento da Faculdade de Serviço Social (FSS) - UERJ foi cadastrado em 2012 com o intuito de potencializar as atividades já realizadas pelo Projeto de Promoção da Saúde (PPS) do Núcleo de Atenção ao Idoso (NAI/UNATI-UERJ), integrando graduação, extensão, assistência e pósgraduação no formato residência. Articula-se com as diversas modalidades de educação em saúde desenvolvidas no PPS, mas enfatiza dois aspectos centrais: a formação de alunos do curso de Serviço Social e a assessoria da equipe multiprofissional, no exercício de práticas educativas.

O Núcleo de Atenção ao Idoso (NAI) é uma unidade de saúde pública no nível secundário vinculada ao Hospital Universitário Pedro Ernesto (HUPE) e a UNATI (UERJ). Foi criado em 1990 "a partir da necessidade de se criar respostas sociais para enfrentar as questões do envelhecimento populacional brasileiro" ${ }^{1}$, e tem como proposta a atenção integral ao idoso com necessidades de saúde mais complexas, a capacitação de 
profissionais de saúde e o desenvolvimento de novas metodologias de trabalho com a população idosa.

O seu programa de ensino inclui modalidades de treinamento para estagiários e bolsistas de projetos de extensão e da graduação, alunos do curso de especialização em geriatria e gerontologia da Universidade Aberta da Terceira Idade (UNATI/UERJ), e residentes de primeiro e segundo ano das áreas de medicina, serviço social, psicologia, nutrição, fisioterapia e enfermagem, supervisionados por preceptores e docentes da universidade, responsáveis pelo projeto político-pedagógico.

A equipe multiprofissional encontra-se inserida em diversos cenários de atuação, que traduzem diferentes níveis de atenção à saúde. Os projetos assistenciais e de ensino seguem a lógica da integralidade da atenção, incluindo ações de acolhimento, assistência ambulatorial, hospitalar, domiciliar e de promoção da saúde.

O Projeto de Promoção da Saúde (PPS) é uma dessas ações, e vem desenvolvendo suas atividades desde o ano de 1996. Comporta um leque diversificado de ações educativas, como grupos de sala de espera, grupo fechado (Encontros com a Saúde), grupo aberto (Roda da Saúde e Encontros sobre promoção da saúde), grupo de trabalho (Idosos Multiplicadores), além da produção de materiais informativos (folders, mural e boletim). Consideramos que diferentes formatos metodológicos alargam os dispositivos de informação, comunicação e educação no serviço, além de alimentar uma cultura profissional mais sensível com as questões socioculturais. ${ }^{2}$

Para esse artigo, serão apresentados os resultados obtidos por análise documental, referentes ao Grupo Roda da $S_{a u ́ d e}{ }^{3}$, do período que compreende os anos de 2012 a 2015. Trataremos dos seguintes eixos: grupos realizados, idosos e profissionais envolvidos, participações, temas debatidos, materiais socioeducativos construídos, com ênfase para os boletins informativos, bem como uma avaliação qualitativa do processo de assessoria e do impacto na formação do aluno de Serviço Social na realização das ações educativas. 


\section{O envelhecimento e as práticas educativas - do que estamos falando?}

O envelhecimento populacional brasileiro vem exigindo respostas mais efetivas às novas demandas colocadas, e, por conseguinte, reforça a necessidade de um modelo assistencial que assegure o pleno direito, em particular, o acesso aos serviços e tecnologias diversas no campo da saúde. $O$ paradoxo instalado pelas desigualdades sociais características da sociedade brasileira demarcam, por um lado, a coexistência de avanços tecnológicos e aumento da expectativa de vida; e por outro, a crescente fragilidade dos idosos em situação de violação de direitos ${ }^{4}$ Logo, o desafio imposto aos profissionais do campo do envelhecimento não se traduz apenas em "boas" práticas sociais e de saúde, mas em uma luta política e organizada por melhores condições de vida.

Partimos do debate sobre saúde e envelhecimento, bem como as recentes reflexões no interior do Serviço Social no que tange às possibilidades de ação com vistas ao fortalecimento do projeto de Reforma Sanitária, dos princípios do $\operatorname{SUS}^{5}$ e a consolidação de um projeto profissional comprometido com os direitos da população idosa. $^{6,7}$

Nesse contexto, a concepção de saúde se alarga e passa a ser considerada como o resultado de processos sociais que incidem sobre a vida e a saúde dos indivíduos. Na área de saúde do idoso esse debate já está consubstanciado na literatura, nas práticas profissionais e na vasta legislação que rege esse campo. Ações que prezem pela atenção integral e que atuem interdisciplinarmente têm sido valorizadas de modo a contemplar as múltiplas necessidades dos idosos. ${ }^{8}$

Consideramos ainda as discussões contemporâneas no âmbito da Promoção da Saúde e da Educação Popular em Saúde6, bem como o potencial da dimensão educativa na reorientação dos serviços, no sentido de garantir a integralidade da atenção e favorecer a consolidação de uma lógica ampliada e participativa dos usuários. A integralidade é compreendida neste trabalho como um olhar abrangente sobre as necessidades de saúde e cuidados $^{9,10}$ viabilizando práticas democráticas que possam considerar os determinantes sociais do processo saúde-doença e estabelecer ações que promovam saúde nas variadas expressões. 
a integralidade implica uma recusa ao reducionismo e à objetivação dos sujeitos, comportando a abertura para o diálogo. Engloba também, a busca por ampliar a percepção das necessidades dos grupos e interrogar-se sobre as melhores formas de responder a tais necessidades. Como princípio norteador das práticas, integralidade pressupõe compreender o outro como sujeito inserido no contexto social e portador de uma história de vida singular, com anseios, crenças e visões de mundo que devem ser reconhecidas e compartilhadas. A lógica de abordagem considera o ser humano integral e não apenas sua condição física e orgânica. ${ }^{4}$

A Política Nacional de Promoção da Saúde ${ }^{11}$ ao indicar medidas de prevenção e promoção da saúde, destaca o recurso educativo como um elemento intrínseco para a área, enfatizando a necessidade do compartilhamento de experiências, e a aproximação entre profissionais e a população. A referência aos princípios teórico-metodológicos da Educação Popular em Saúde alinha-se às preocupações com riscos ideológicos da promoção quando esta é reduzida, na prática, a uma questão de escolhas individuais. A abordagem sobre comportamentos saudáveis deve incluir a reflexão sobre a produção social da saúde-doença e reconhecer o contexto pessoal, cultural e político como dimensões relevantes na dinâmica das ações educativas. Pela complexidade aí envolvida, parâmetros como ética, diálogo e valorização do outro e de seus saberes devem ser especialmente considerados na relação entre profissionais e idosos. ${ }^{6}$

\section{O grupo em questão: Roda da Saúde}

O grupo Roda da Saúde foi criado em 2005 como uma estratégia de continuidade da participação dos idosos nas atividades educativas. Seu principal objetivo é a discussão sobre temas relacionados à saúde e a qualidade de vida no envelhecimento, assim como outros temas emergentes e demandados pelos participantes. Trata-se de um grupo aberto que não exige inscrição prévia e ocorre uma vez por semana com duração de duas horas. Caracteriza-se como um "chá da tarde" e apresenta o seguinte desenvolvimento:

O momento de acolhida ocorre no início do encontro, onde a equipe apresenta os participantes novos, como também incentiva um veterano a explicar o que é o grupo, e aproveita o momento também para dar informes gerais. Na chegada, o idoso é recebido 
por um profissional da equipe, que lhe fornece um crachá, sem nada escrito, para que ele mesmo o confeccione e formule criativamente como quer ser nomeado. Ademais, o novo integrante recebe ainda uma ficha de primeira vez para preencher, com o auxílio de algum membro da equipe, contendo seus dados pessoais e a forma de inserção no serviço.

Após a acolhida, temos o aquecimento, que, na maioria das vezes, se inicia com a indagação aos idosos sobre o que eles conhecem acerca do conteúdo da reunião, visando o levantamento das diferentes vivências sobre o tema. Nesse tópico, a proposta principal é problematizar o assunto a partir das questões trazidas pelos idosos, deixandoos à vontade para prosseguir com a discussão. No decorrer da dinâmica, o coordenador aproveita essas questões trazidas para incrementar o debate, não se utilizando do seu conhecimento para assumir uma postura impositiva, ou seja, ditando o que é certo ou errado, e sim recorrendo ao diálogo, como forma de possibilitar a troca.

Em seguida, tem-se o desenvolvimento do tema, que é guiado muitas vezes por uma dinâmica de grupo, cujo objetivo é estimular a participação do idoso e aprofundar a discussão, possibilitando aos usuários partirem de experiências concretas da realidade, de modo a construírem "leituras" e projetos coletivos de intervenção sobre ela.

A criação das dinâmicas segue o princípio de privilegiar o diálogo, a vivência e
a participação de todos em um espaço acolhedor e prazeroso. A
heterogeneidade do grupo deve ser considerada e as diferenças reconhecidas a
fim de viabilizar a inclusão apesar de eventuais limites. Em certos momentos,
por exemplo, a opção de realizar atividades de leitura e escrita, mesmo com
idosos semianalfabetos no grupo, é feita mediante o apoio direto da
coordenação. A discussão em pequenos grupos ou duplas, por sua vez, pode ser
estratégia para maior participação daqueles que se sentem menos à vontade
para se expressar no grupo maior.

Prosseguindo, temos o resumo do encontro, momento em que sintetizamos o que foi exposto, fazendo outras articulações com a vida cotidiana. Nesse aspecto, pensamos nos limites e possibilidades de mudanças e no compartilhamento do aprendizado que nos foi propiciado. 
É estimulada a expressão das possibilidades e limites dos participantes na relação com novos conhecimentos e seus significados à luz dos distintos contextos de vida. O coordenador deve construir pequenas sínteses, articulando as falas, e suscitar a percepção sobre o quanto uma questão individual trazida é vivida por outros também, coletivizando e fortalecendo o intercâmbio de experiências. ${ }^{3}$

E para findar, temos o encerramento com o chá, que é uma maneira de aproximar equipe e usuários. Nessa ocasião, os idosos tiram dúvidas, trazem questões e demandas específicas.

Temos ainda a produção de boletins informativos, de periodicidade mensal, que buscam compartilhar as informações e sistematizar as reflexões construídas no grupo.

\section{Os resultados}

A metodologia utilizada para esse estudo centrou-se no levantamento e análise dos dados das fichas de identificação dos idosos, denominada 'ficha de primeira vez', relatórios de reuniões e relatórios semestrais elaborados pela equipe multiprofissional durante o período supracitado. Analisamos ainda os documentos acadêmicos semestrais produzidos pelos alunos estagiários e extensionistas, bem como os relatórios anuais da coordenação do projeto de extensão.

Para a descrição dos resultados do nosso projeto é preciso delinear três eixos principais: o exercício metodológico experimentado nos grupos e na construção dos boletins informativos; a assessoria realizada às equipes multiprofissionais e a avaliação.

$\mathrm{Na}$ realização dos grupos, adota-se o enfoque da educação popular em saúde (como já apresentado anteriormente), cujo ponto de partida é o contexto de vida e o conhecimento da população sobre as temáticas trabalhadas. ${ }^{12}$ A perspectiva é da construção conjunta de uma reflexão ou a aquisição de um novo conhecimento que faça sentido para os sujeitos que participam do processo educativo. Nessa direção, as modalidades metodológicas devem privilegiar atividades que facilitem o engajamento propositivo. Já os boletins informativos seguem os fundamentos da comunicação e saúde e devem ser ferramentas que fomentem a reflexão, a curiosidade e a indagação, 
contrapondo-se aos materiais de cunho normativo ou prescritivo, do tipo "faça isso, não faça aquilo". ${ }^{13}$ A assessoria às equipes segue a mesma ideia, de modo a garantir um espaço plural de debate sobre as expectativas, experiências e os princípios da referência teórica do projeto. ${ }^{14}$

O processo de avaliação do projeto envolve a aplicação de instrumentos próprios junto aos idosos e à equipe.

O processo de avaliação de uma atividade educativa como o Roda da Saúde é complexo, dado o caráter aberto e multitemático de suas ações. Na busca de caminhos, é fundamental o planejamento cuidadoso e mecanismos de avaliação contínuos e sistemáticos. Nesse ângulo, a avaliação precisa captar elementos do dia a dia do trabalho, a perspectiva dos participantes e equipe, mas também se articular ao todo, produzindo novos elementos de análise e indicadores que retroalimentem o planejamento. ${ }^{3}$

Por esse motivo, a avaliação é realizada nos seguintes momentos: a) no contexto das atividades educativas juntamente aos idosos e a partir de suas concepções acerca do trabalho desenvolvido; b) avaliação processual da equipe imediatamente após a realização das atividades através de um roteiro de questões; c) semestralmente, através de avaliação geral dos alunos envolvidos no projeto realçando elementos como expectativas em relação ao trabalho desenvolvido, conteúdos e habilidades apreendidos, relação com idosos, a experiência na coordenação de grupos e sua sistematização, dificuldades e facilidades, etc.; d) semestralmente, com sistematização dos dados quantitativos e qualitativos do grupo; e) anualmente, no período de recadastramento e relatório de atividades de extensão, e participação na UERJ sem muros.

Realizamos no período citado 88 encontros do Grupo Roda da Saúde e 28 boletins informativos, envolvendo cerca de 243 idosos, 47 residentes de diferentes profissões da saúde (Serviço Social, Enfermagem, Fisioterapia, Nutrição e Medicina), 8 bolsistas de extensão (Serviço Social e Nutrição) e 08 coordenadores/preceptores.

Foram trabalhados aproximadamente 83 temas, gestados na própria dinâmica do grupo e vinculados à realidade, desde eleições, sexualidade, medicamentos, família, relação médico-paciente, estatuto do idoso, depressão, dentre vários outros, compondo ampla diversidade. 
A média tem sido de 10 idosos por encontro, o que impõe a construção de estratégias que possibilitem a expressão e o "fazer" democrático, sem perder a qualidade das reflexões e das relações construídas no grupo. Cada encontro é único e particular, pois além da pluralidade temática, há ainda a heterogeneidade dos participantes, como veremos a seguir.

Os idosos são, em sua maioria, mulheres acima de 70 anos. Estudo realizado em 201515 revelou que $88 \%$ dos membros do grupo era do sexo feminino e que $51 \%$ tinha entre 70 e 80 anos e 15\% estava acima dos 80 anos. A escolaridade varia de semianalfabetos a pós-graduados. Há idosos em distintas situações de vida, desde os mais solitários, sem vínculos familiares ou em processo de fragilização, até pessoas independentes, autônomas e com laços sociais preservados. São moradores na área geográfica de abrangência da instituição, mas coexistem idosos moradores de áreas mais distantes e até fora do município do RJ.,15

Tais dados demonstram uma tendência observada pelos estudos demográficos 16, com o destaque para o aumento da população acima de 80 anos e da maior prevalência de mulheres. Em 2014, a expectativa de vida ao nascer do brasileiro foi estimada em 78,8 para mulheres e 71,6 para homens; e houve aumento no grupo de 80 anos ou mais de idade na população, que passou de 1,2\%, em 2004, para $1,9 \%$.

O aumento específico da população acima de 80 anos, em meio ao crescimento do número de idosos, é reconhecido como o dado demográfico mais significativo, por ser este o grupo que apresenta maior carga de doenças crônicas e incapacidades, e por consequência, a maior demanda de cuidados continuados. A feminilização do envelhecimento, isto é, a presença cada vez maior de mulheres na população idosa conforme o avançar da idade, por outro lado, exige uma atenção diferenciada para as questões de gênero, em virtude das marcas históricas de desigualdade desse segmento populacional. ${ }^{4}$

Essa caracterização exige dos coordenadores a devida atenção para o "novo" que emerge do encontro grupal e, por conseguinte, para a flexibilidade necessária do planejamento, sem, contudo, negligenciar a programação dos passos metodológicos que orientarão cada grupo realizado. 
A heterogeneidade do grupo deve ser considerada e as diferenças reconhecidas a fim de viabilizar a inclusão apesar de eventuais limites. Em certos momentos, por exemplo, a opção de realizar atividades de leitura e escrita, mesmo com idosos semianalfabetos no grupo, é feita mediante o apoio direto da coordenação. A discussão em pequenos grupos ou duplas, por sua vez, pode ser estratégia para maior participação daqueles que se sentem menos à vontade para se expressar no grupo maior. ${ }^{3}$

Os eixos mais destacados pelos idosos foram a construção de laços e vínculos, a aquisição de novos conhecimentos e o formato da atividade. Reconhecem os temas trabalhados como pertinentes e apropriados para as suas experiências, além de expressarem a intenção de realizarem mudanças de hábitos em suas vidas.

"Aqui tem todo tipo de pessoas, venho aqui por prazer"; "Aqui encontrei amizade, não tem preconceito"; "Começo a me preparar para o Roda desde 5a feira". "Fiquei até doente sem o roda"; "Aprendi coisas novas"; "Tem controle do tempo, mas, ao mesmo tempo, é permitida a fala de todos e a participação na sugestão de novos temas"; “Aqui não se fala só de doença, e sim de saúde”. ${ }^{3}$

O boletim informativo criou novos canais de conversações, privilegiando não apenas os temas discutidos no grupo, mas, sobretudo o reforço ao acesso às informações debatidas, socializando as reflexões e produções dos participantes. Configurou-se em um recurso bastante vigoroso na conexão entre os encontros e das criações realizadas. A periodicidade do boletim tem sido mensal, de modo a não caracterizar uma distância entre a realização da atividade e sua sistematização.

A assessoria das equipes vem se consolidando como um espaço de educação permanente dos coordenadores e profissionais em formação. Realizamos no período, o treinamento geral das equipes com carga horária de 80 hs e supervisão semanal de 2 hs, além de ministrar aula específica em curso de especialização em geriatria e gerontologia. As atividades de assessoria têm sido realizadas sistematicamente, com diferentes metodologias, e caracteriza-se como um importante lócus de propagação da prática educativa em saúde na instituição. A relevância da assessoria neste projeto se dá pela tendência das equipes assumirem o enfoque de educação em saúde em uma vertente mais preventivista. Nesse sentido, a assessoria se articula com um processo de supervisão, particularmente da equipe de assistentes sociais como multiplicadores na desconstrução e reconstrução das bases críticas do trabalho. Acreditamos que a ação educativa que segue o 
caminho democrático da construção coletiva pode indicar um significativo recurso para reorientar os serviços e gerar mudanças a partir do lugar que cada profissional e idoso ocupa na sociedade.

A linha de pesquisa prevista no projeto - estudo do impacto das ações educativas na qualidade de vida dos idosos - tem sido incorporada no universo das atividades de ensino programadas pelos projetos parceiros (Projeto de Promoção da Saúde e Projeto Nutrição e Terceira Idade).

\section{A participação social e sua importância no envelhecimento}

Consideramos, portanto, que a participação social e política do idoso é um instrumento de grande valia para o alcance dos direitos sociais que, apesar de estarem dispostos em lei, na prática não são efetivados. Tomamos como referência a concepção de participação social como um processo mediante o qual diversas camadas sociais "tomam parte na produção, na gestão e no usufruto dos bens de uma sociedade historicamente determinada". ${ }^{17}$ Tendo em vista as desigualdades ainda presentes na sociedade, alcançar a velhice para muitos é sinônimo de satisfação, mesmo com tantas adversidades encontradas no caminho ao longo da vida. Essa etapa da vida para o idoso deveria ser um momento de usufruto dos direitos, ou seja, o momento de aproveitar tudo o que colheu no passado.

A importância da participação social e política dessa parcela da sociedade se faz permanentemente necessária para empreender mecanismos de superação no que tange ao descaso para com o idoso. Por esse ângulo, ações devem ser fomentadas com o objetivo de garantir a participação dos mais velhos em espaços de controle social, a fim de colocar na agenda pública as insatisfações que vem inquietando grande parte dos idosos.

Os programas de terceira idade têm o potencial de promover a recuperação da memória, o acolhimento e o compartilhamento das situações difíceis, além de propiciar novos conhecimentos e o desenvolvimento de novas habilidades. ${ }^{17}$ Como verificamos nos relatos do grupo Roda da Saúde, os idosos informam que se sentem satisfeitos com a 
criação de vínculos que esses espaços lhes proporcionam, como também a troca de experiência através da relação intergeracional.

Tal participação possibilita ao idoso apresentar para a sociedade um novo olhar sobre a velhice, ao expor suas capacidades, suas experiências de vida e sabedoria adquiridas ao longo dos anos, o que permite a alguns repensar a representação social da velhice, que ainda é um tanto negativa.

Com efeito, os espaços formais na sociedade ainda são incipientes e esse fato impossibilita a efetivação do que dispõe a legislação vigente - "assegurar os direitos sociais do idoso, criando condições para promover sua autonomia, integração e participação efetiva na sociedade" ${ }^{18}$

É interessante sublinhar que o grupo "Roda da Saúde" encontra-se em consonância com o que dispõe a legislação e a literatura da área pois constitui um espaço concreto de participação social e política. Além de favorecer ao idoso possibilidades de ampliação de seu conhecimento, viabiliza um espaço de aprendizado, onde a diferença, ao contrário de ser escamoteada, é valorizada através das experiências e trajetórias de cada idoso.

\footnotetext{
"é através de um processo de educação permanente e de educação e saúde que os usuários dos nossos serviços podem assumir uma nova posição frente às situações do seu cotidiano, desenvolvendo potencialidades, muitas vezes adormecidas, novas habilidades, além de acionar a capacidade crítica de organização e luta pela garantia de direitos em nossa sociedade". ${ }^{17}$
}

\section{Arremates finais: o Serviço Social e as práticas educativas - o impacto na formação}

As ações socioeducativas realizadas no âmbito da intervenção profissional do assistente social estão embasadas sobre dois pilares ${ }^{19}$. $O$ primeiro diz respeito à socialização de informação no seu sentido mais amplo, considerando o direito do usuário a ter acesso e usufruir de todo o conhecimento socialmente produzido necessário para a melhoria das suas condições de vida. O Código de Ética dos Assistentes Sociais de 1993, em seu $10^{\circ}$ princípio, afirma que é nosso dever exercer a ação cotidiana tendo "compromisso com a qualidade dos serviços prestados à população e com o aprimoramento intelectual, na perspectiva da competência profissional”. O outro pilar se 
refere ao processo reflexivo desenvolvido no percurso da relação estabelecida entre profissionais e usuários, pautando-se no princípio de que as demandas trazidas à instituição por ações individuais ou através de grupos são matéria-prima para formação de consciências críticas.

Segundo essa perspectiva, o assistente social nas práticas educativas deve refletir junto com o usuário de modo que "este consiga captar, na medida do possível, o movimento da realidade social e, consequentemente, participar, de forma consciente do processo de transformação dessa realidade enquanto ser histórico”. ${ }^{20}$ Para lutar por melhores condições de vida e de trabalho, não basta somente estar organizado; é necessário que os usuários tenham acesso a um saber que possa servir de base para instrumentalizá-los. Um ser humano crítico que saiba reivindicar e tenha clareza do que está reivindicando, torna-se mais capaz de apreender o movimento da realidade social e, assim, tem mais possibilidades de compreender as lutas sociais como caminhos para a viabilização de suas demandas.

Nessa lógica, os indivíduos _ ao trazerem suas questões ao grupo, permite ao assistente social provocar a autorreflexão. Como se pode fazer isso? Problematizando o que foi exposto, fazendo com que o sujeito se pergunte, questione sobre o seu cotidiano e de maneira consciente e crítica reflita sobre suas condições de vida, bem como as formas coletivas de enfrentamento das desigualdades.

O fato de os usuários adquirirem conhecimento através da participação em grupos, possibilita ao mesmo uma maior segurança para a resolução de suas questões na busca de acesso aos direitos nos serviços disponíveis. Consequentemente, o processo grupal através das informações e trocas de experiências pode favorecer ao usuário tornarse mais engajado e desvendar determinada realidade.

A parceria com o projeto do Núcleo de Atenção ao Idoso favoreceu a participação dos alunos da graduação do Serviço Social em múltiplos cenários de aprendizagem na área da saúde do idoso, com supervisão técnica de assistente social da equipe e interação com os demais profissionais, assegurando a vivência do trabalho em equipe interdisciplinar. Para esse aluno, o projeto amplia o circuito das experiências, 
estimulando a interação entre o aluno da graduação e residentes de várias áreas de formação, oportunizando trocas entre profissões distintas e aprendizagens em níveis diferenciados; e reafirma os princípios éticos e políticos da profissão.

A metodologia educativa crítica provoca um redimensionamento nas práticas cristalizadas e conservadoras de educação e saúde, estabelecendo o contato com novos paradigmas em saúde e com dispositivos assistenciais que priorizem o sujeito e seu contexto de vida. $\mathrm{O}$ projeto facilita a aproximação com metodologias problematizadoras da realidade, planejamento de atividades educativas, execução e coordenação de grupos, etapa de avaliação e sistematização, construção de materiais socioeducativos, etc.

No ano de 2014, o projeto de extensão desdobrou-se em campo de estágio curricular obrigatório para alunos da FSS/UERJ, proporcionando a abertura de novos locais de trabalho para a formação do estudante. Atualmente há 05 vagas de estágio curricular, com estimativa de ampliação, e uma disciplina de estágio supervisionado específica.

\section{Conclusões}

O aumento progressivo de idosos no país vem demandando, principalmente, dos profissionais da área da saúde, qualificação teórica e técnica para atuar diante das questões do envelhecimento. Isto posto, torna-se essencial ampliar e garantir os espaços de formação profissional e de participação social dos idosos.

As ações educativas na saúde e na área do envelhecimento têm sido fundamentais para a discussão sobre a importância de aquisição de novos hábitos e sua relação direta com os condicionantes sociais de vida. Essa vertente redimensiona o olhar sobre o campo e permite construir práticas mais democráticas e com a plena participação do usuário no seu processo de cuidados, sem desconsiderar ou despolitizar os processos sociais que geram as condições de vida e saúde.

Espera-se que este texto possa ilustrar o exercício de ações educativas que busquem superar o modelo vertical predominante e que estimule o desenvolvimento do potencial dos serviços de saúde para práticas articuladas, criativas e politizantes, centradas no usuário e no direito à vida. ${ }^{4}$ 
O fomento à participação visa criar ambientes de reflexão sobre temas de saúde e envelhecimento, bem como garantir um efetivo protagonismo dos idosos, problematizando os modelos de atenção, as políticas públicas, os estereótipos do envelhecimento e as melhores estratégias para o autocuidado. Assim, a formação profissional a partir dessa proposta, enseja a replicação nos espaços assistenciais propriamente ditos, criando mecanismos de maior abertura dos serviços para as reais necessidades de saúde da população usuária.

\section{Agradecimentos}

Agradecemos aos coordenadores do Projeto de Promoção da Saúde do NAI/Unati Liliane Carvalho Pacheco e Liv Katiuska - pelo apoio para a realização desse projeto e por garantir pleno acesso a documentação.

\section{Contribuição dos autores}

Maria Helena de J. Bernardo colaborou na organização, redação e revisão do texto.

Dayara da Silva Ferreira colaborou na redação, revisão do texto e levantamento de dados. As demais bolsistas colaboraram no levantamento de dados e na redação do texto.

\section{Referências}

1. MOTTA, L., Caldas, C.P. e Assis, M. A formação de profissionais para a atenção integral à saúde do idoso: a experiência interdisciplinar do NAI/UnATI. . Revista Ciência \& Saúde Coletiva, 2006.

2. ASSIS, M. et al. Ações educativas em promoção da saúde no envelhecimento: A experiência do Núcleo de Atenção ao idoso da UNATI/UERJ. Revista O Mundo da Saúde, do Centro Universitário São Camilo. São Paulo, março de 2007. 
3. BERNARDO, M.H.J. et al. A saúde no diálogo com a vida cotidiana: a experiência do trabalho educativo com idosos no grupo Roda da Saúde. Revista de Atenção primária em Saúde, 2009.

4. BERNARDO, M.H.J. e ASSIS, M. A saúde do idoso e a integralidade da atenção. In Duarte et al (org). Coletânea Política de Saúde Hoje: Interfaces \& Desafios no Trabalho de Assistentes Sociais. CESSS - FSS/UERJ. Campinas, SP. Editora Papel Social. 2014. p.317-333.

5. BRAVO, M. I. S. e MATOS, M. C. "Projeto Ético-Político do Serviço Social e sua Relação com a Reforma Sanitária: elementos para o debate”. In: MOTA, Ana Elizabeth. et al (Orgs) Serviço Social e Saúde: Formação e Trabalho Profissional. São Paulo: Cortez; Brasília: OPAS, OMS, Ministério da Saúde; Recife: ABEPSS, 2006. Disponível em: <http://www.fnepas.org.br/pdf/servico_social_saude/texto2-3.pdf

6. ASSIS, Mônica de. Envelhecimento ativo e promoção da saúde: reflexão para as ações educativas com idosos. Revista de Atenção Primária à Saúde. RJ, 2005.

7. BERNARDO, M.H.J. et al. O potencial das ações educativas no campo do envelhecimento: a experiência do Serviço Social no NAI/UNATI-UERJ. Anais da19a Conferência Mundial de Serviço Social. Salvador - BA, agosto de 2008.

8. BERNARDO, M.H.J. Avaliação social do idoso e do cuidador. NAI/Unati-UERJ. 2016 (texto didático)

9. CECILIO, L.C.O. As necessidades de saúde como conceito estruturante na luta pela integralidade e equidade na atenção em saúde. In: Mattos, R.A. e Pinheiro, R. (org). Os sentidos da integralidade na atenção e no cuidado a saúde. Rio de Janeiro: IMS/UERJ, ABRASCO, 2001.

10. MATTOS, R.A. Cuidado prudente para uma vida decente. In: Pinheiro, R. e Mattos, R.A. Cuidado, as fronteiras da integralidade. Rio de Janeiro, Lappis. UERJ. Abrasco, 2004.

11. BRASIL. Política Nacional de Promoção da Saúde. Brasília, 2006.

12. STOTZ, Eduardo. Enfoques sobre educação popular e saúde. In: Caderno de educação popular e saúde. Brasília: Ministério da Saúde, 2007, p. 46-57. (Série B. Textos 
$\begin{array}{llll}\text { Básicos } & \text { de } & \text { Saúde: } & \text { disponível }\end{array}$ http://bvsms.saude.gov.br/bvs/publicacoes/caderno_educacao_popular_saude_p1.pdf)

13. BRASIL. Caderno de educação popular e saúde. Brasília: Ministério da Saúde, 2007. (Série B. Textos Básicos de Saúde: disponível em http://www.saude.gov.br/bvs)

14. MATOS, M.C. Assessoria e Consultoria: reflexões para o Serviço Social. In: Bravo, M.I.S. e Matos, M.C. Assessoria, Consultoria e Serviço Social. Rio de Janeiro, 7 Letras, FAPERJ, 2006.

15. FERREIRA, D. S. Perfil dos idosos participantes do Grupo Roda da Saúde: uma análise dos últimos dez anos de existência do grupo. Trabalho de Conclusão de Curso Faculdade de Serviço Social /UERJ, janeiro, 2016.

16. Instituto Brasileiro de Geografia e Estatística - IBGE. Síntese de Indicadores Sociais: Uma análise das condições de vida da população brasileira. 2015.

17. NUNES, A.T.G.L. As Mulheres na Universidade da Terceira Idade: Busca por novas formas de envelhecer. In: PAZ, Serafim e outros (Org.). Envelhecer com Cidadania: quem sabe um dia? Rio de Janeiro: CBCISS; ANG/Seção Rio de Janeiro, 2000.

18. BRASIL. Política Nacional do Idoso. Brasília, 1994.

19. MIOTO, R.C.T. Orientações e acompanhamento social a Indivíduos, grupos e famílias In: CFESS/ABEPSS. Serviço Social: Direitos- Sociais e Competências Profissionais. Brasília, CFESS/ABEPSS. 2009.

20. VASCONCELOS, Ana Maria. Serviço social e prática reflexiva. In: Em Pauta. Revista da Faculdade de Serviço Social da UERJ. No 1, Rio de Janeiro, UERJ, 1993. 